\title{
Occurrence and Impact of Time Delay to Primary Percutaneous Coronary Intervention in Patients With ST-Segment Elevation Myocardial Infarction
}

\author{
Mohammady Shahin ${ }^{\mathrm{a}, \mathrm{e}}$, Slayman Obeid ${ }^{\mathrm{a}, \mathrm{e}}$, Lotfy Hamed ${ }^{\mathrm{b}}$, Christian Templin ${ }^{\mathrm{a}}$, Oliver Gamperlia, \\ Fabian Nietlispach ${ }^{\mathrm{a}}$, Willbald Maier ${ }^{\mathrm{a}}$, Nooraldaem Yousif ${ }^{\mathrm{a}}$, Francois Mach ${ }^{\mathrm{c}}$, Marco Roffic ${ }^{\mathrm{c}}$, \\ Stephan Windeckerd, Lorenz Raber ${ }^{\mathrm{d}}$, Christian M. Matter ${ }^{\mathrm{a}}$, \\ Thomas F. Luscher ${ }^{\mathrm{a}, \mathrm{f}}$
}

\begin{abstract}
Background: The aim of the study was to evaluate the occurrence, duration and impact of time delays to primary percutaneous coronary intervention (pPCI) in ST-segment elevation myocardial infarction (STEMI).

Methods: A total of 357 consecutive STEMI patients enrolled in the prospective Special Program University Medicine ACS (SPUMACS) cohort were included. In order to identify the causes behind a possible treatment delay, we constructed four different time points which included: 1) symptom onset to hospital arrival, 2) hospital arrival to arrival in the catheterization laboratory, 3) hospital arrival to first balloon inflation, and 4) time from arrival in the catheterization laboratory to first balloon inflation in addition to total ischemic time. Patients were stratified according to a delay $>3 \mathrm{~h},>30 \mathrm{~min},>90 \mathrm{~min}$ and $>1 \mathrm{~h}$, respectively and major adverse events at 0,30 and 365 days were analyzed.
\end{abstract}

Results: Resuscitated STEMI patients (23 patients) and STEMI patients presenting at weekends (101 patients) and to lesser extent at night hours (100 patients) experienced more time delays than stable patients and those presenting at office hours. Median door-to-balloon time averaged $93 \mathrm{~min}$ in resuscitated, but $65 \mathrm{~min}$ in stable patients. Median door-to-balloon time at weekends and public holidays was 89 min, but $68 \mathrm{~min}$ at office hours. Median time from hospital arrival to cathlab arrival at weekends and public holidays was $30 \mathrm{~min}$, but 15

Manuscript submitted September 20, 2017, accepted October 3, 2017

aDepartment of Cardiology, University Heart Center, Zurich, Switzerland ${ }^{b}$ Department of Internal Medicine, University Hospital Sohag, Egypt

${ }^{\mathrm{c} C}$ ardiovascular Center, Department of Cardiology, University Hospital Geneva, Switzerland

${ }^{\mathrm{d} C}$ Cardiovascular Center, Department of Cardiology, University Hospital Bern, Switzerland

${ }^{\text {e}}$ These authors shared first authorship

${ }^{f}$ Corresponding Author: Thomas F. Luscher, Department of Cardiology, University Heart Center, Ramistrasse 100, CH-8091 Zurich, Switzerland.

Email: thomas.luescher@usz.ch

doi: https://doi.org/10.14740/cr612w min during office hours. Corresponding times for resuscitated patients was 45 and $15 \mathrm{~min}$ in stable patients. Of note, resuscitated patients were late presenters as regards time from symptoms onset to hospital arrival with a median time of 180 min compared to $155 \mathrm{~min}$ in stable patients. Median total ischemic time was $225 \mathrm{~min}$ for all patients, 223 $\mathrm{min}$ at day hours, 239 at night hours, $244 \mathrm{~min}$ at weekends, $233 \mathrm{~min}$ at office days, $220 \mathrm{~min}$ in stable patients and $273 \mathrm{~min}$ in resuscitated patients. Patients with STEMI who arrived $>3 \mathrm{~h}$ after symptom onset had a higher rate of myocardial infarction (MI) at 1 year (1.6\% vs. $9 \%$ in $<3 \mathrm{~h}$; $\mathrm{P}=0.008$ ). Furthermore, STEMI patients who had a delay of $>1 \mathrm{~h}$ from cathlab arrival to first balloon inflation had a higher rate of in hospital reinfarction at 0 day $(0.6 \%$ vs. $0 \%$ in $<1 \mathrm{~h} ; \mathrm{P}=$ $0.007)$, $\mathrm{MI}$ at 30 days $(0.8 \%$ vs. $0 \%$ in $<1 \mathrm{~h} ; \mathrm{P}=0.001)$ and $\mathrm{MI}$ at 1 year $(1.4 \%$ vs. $1.1 \%$ in $<1 \mathrm{~h} ; \mathrm{P}=0.012)$. Similarly, in these patients, cardiac deaths at 0 day $(0.8 \%$ vs. $0.6 \%$ in $<1 \mathrm{~h} ; \mathrm{P}=0.035)$ and at 30 days $(0.8 \%$ vs. $0.6 \%$ in $<1 \mathrm{~h} ; \mathrm{P}=0.035)$ were higher as were major adverse cardiovascular events (MACCE) at 0 day (1.4\% vs. $0.8 \%$ in $<1 \mathrm{~h} ; \mathrm{P}=0.004)$.

Conclusion: Resuscitated STEMI patients and those presenting at weekends and to lesser extent at night hours experienced more time delays and longer ischemic time than stable patients and those presenting at office hours. In STEMI patients, any delay in treatment increased their risk of MACCE. Efforts should focus on improving patient's awareness along with minimizing in-hospital transfer to the catheterization laboratory especially at weekends and in resuscitated patients.

Keywords: Time delay to angioplasty; Acute coronary syndromes; Basic and outcome difference according time delays

\section{Introduction}

There is general consensus that proper timing of reperfusion therapy is very critical in the management of ST-segment elevation myocardial infarction (STEMI) patients, with the greatest benefit (i.e. salvage of the viable myocardium) seen in those undergoing reperfusion therapy within the first $2-3$ $\mathrm{h}$ of symptom onset $[1,2]$. Current treatment strategies aim to 
provide optimal care, while minimizing delays in order to improve clinical outcomes. However, there still remains a wide range of logistic problems including patient delays and inhospital transfer which can render treatment goals unachievable. Reduction of first-medical-contact-to-balloon time relies on efficient coordination of care between first medical contact or referral hospitals, the emergency medical service and the receiving hospitals. It is estimated that about two-thirds of patients achieve a guideline-recommended overall first-hospitaldoor-to-balloon time of $120 \mathrm{~min}$. It has been recommended that in patients referred to or presenting to percutaneous coronary intervention (PCI)-capable centers, door-to-balloon time should be less than $60 \mathrm{~min}$. On the other hand, in order to shorten reperfusion delays and lower in-hospital mortality, transfer from a non-PCI-capable center is advisable to occur within $30 \mathrm{~min}$, which is normally referred to as door-in-todoor-out time.

\section{Methods}

\section{Study population}

The prospective multi-center Special Program University Medicine (SPUM) - ACS Biomarker cohort (ClinicalTrials. gov number, NCT01000701) recruited 2,200 patients who were referred for coronary angiography with a diagnosis of acute coronary syndrome (ACS) to one of the participating Swiss University Hospitals (Zurich, Bern, Lausanne, and Geneva) between December 2009 and October 2012. It comprised consecutive recruitment and follow-up performed at 30 days (phone call) and 1 year (clinical visit). Female and male patients aged 18 years or older presenting within 5 days after pain onset with the main diagnosis of STEMI, non-ST-elevation myocardial infarction (NSTEMI) or unstable angina (UA) were included.

Within this consortium, a centralized electronic database was implemented providing comprehensive information on all patients. All adverse events occurring within 365 days after the index ACS event were ascertained at 30 days (telephone visit) and 1 year (clinical visit) and adjudicated by an independent adjudication committee consisting of three experienced cardiologists (Lukas Kappenberger, MD, Lausanne; TizianoMoccetti, MD, Lugano; Mathias E. Pfisterer, Basel, chair). In the current study, only patients recruited at the University Hospital Zurich were analyzed. The study was approved by the local ethics committee and all patients gave informed consent.

\section{Patient selection}

Included patients had symptoms compatible with angina pectoris (chest pain and dyspnea) and fulfilled at least one of the following criteria: 1) electrocardiogram (ECG) changes such as persistent ST-segment elevation or depression, T-inversion or dynamic ECG changes, new left bundle branch block (LBBB); 2) evidence of positive (predominantly convention- al) troponin by local laboratory reference values with a rise and/or fall in serial troponin levels; 3) known coronary artery disease (CAD), specified as status after myocardial infarction (MI), previous PCI or newly documented $\geq 50 \%$ stenosis of an epicardial coronary artery during the initial catheterization. Exclusion criteria comprised referral to either coronary artery bypass graft (CABG) or medical management after completion of the coronary angiogram, severe physical disability, and inability to comprehend study or less than 1 year of life expectancy for non-cardiac reasons.

\section{Endpoint definitions}

All-cause mortality included cardiac, vascular and non-cardiovascular causes of death. Cerebrovascular events comprised stroke or transient ischemic attack; repeat revascularization included any repeat coronary revascularization (target and nontarget vessel). MI was defined based on the universal definition including peri-procedural MI in patients with UA [3].

\section{Study endpoints}

The primary endpoint of our study was adjudicated all-cause mortality in hospital, at 1-month and 1-year follow-ups. The secondary endpoints were major adverse cardiovascular events (MACCE), defined as a composite of all-cause mortality, cerebrovascular event, any repeat revascularization and MI in hospital (reinfarction) at 1 month and 1 year, and stent thrombosis in hospital, at 1 month and 1 year follow-ups.

\section{Time intervals}

For all patients, four time intervals were determined: 1) time from symptoms onset to hospital arrival: it is well known that the greatest benefit (i.e. salvage of the viable myocardium) is seen in those undergoing reperfusion therapy within the first 2 - 3 h of symptom onset [1, 2, 4, 5], so we divided our patients in two groups (within $3 \mathrm{~h}$ or longer than $3 \mathrm{~h}$ ); 2) time from hospital arrival to arrival in the catheterization laboratory: we construct it as stated by last AHA recommendation for STEMI system of care 2016 that considered maximum of 30 min for cathlab team to be ready from STEMI activation call (within $30 \mathrm{~min}$ or after $30 \mathrm{~min}$ ); 3) time from hospital arrival to first balloon inflation as it is stated by last ESC and AHA guidelines to be within $90 \mathrm{~min}$ as a maximum (we divided patients to two groups door-to-balloon time within $90 \mathrm{~min}$ or after $90 \mathrm{~min}$ ); and 4) time from arrival in the catheterization laboratory to first balloon inflation (within $60 \mathrm{~min}$ and after $60 \mathrm{~min}$ ), in addition to total ischemic time in minutes in relation to time of presentation and resuscitation.

\section{Statistical analysis}

All continuous variables were statistically described in terms 
of median values as data were not normally distributed; categorical variables were presented as frequency (percentages) and were compared using Chi-square test. $\mathrm{P}$ values were used to describe significance. Statistical significance was set as a P value $<0.05$. All statistical calculations were done using Statistical Package for Social Sciences (SPSS for Windows) software (version 20.0, SPSS Inc., Chicago, IL, USA).

\section{Results}

\section{Type of ACS}

A total of 357 consecutive STEMI patients from Zurich enrolled in the prospective Special Program University Medicine ACS (SPUM-ACS) cohort were included.

\section{Baseline characteristics}

Their mean age was 62.3 years (range: 32 - 91.6 years), $81 \%$ were males, $43.4 \%$ were current smokers, $66.4 \%$ had hypercholesterolemia, $54.3 \%$ were hypertensive and $15.1 \%$ diabetics. A positive family history for CAD was noted in $21.6 \%$ and $8.1 \%$ had a previous $\mathrm{MI}, 9 \%$ had undergone PCI previously and $2.5 \%$ CABG. Of the patients, $2.2 \%$ had a history of previous stroke. At entry, $8.9 \%$ of the patients had been resuscitated (Table 1).

\section{Clinical outcomes}

Overall mortality was $1.7 \%$ at day 0 , still $1.7 \%$ at 30 days and $3.6 \%$ at 1 year, while cardiac death was $1.4 \%$ at day 0 , remained at $1.4 \%$ at 30 days and was $2.2 \%$ at 1 year. MACCE were $2.2 \%$ at day $0,3.6 \%$ at 30 days and $7.8 \%$ at 1 year. The percentage of those with recurrent MI was $0.6 \%$ at day 0 (in hospital reinfarction), $0.8 \%$ at 30 days and $2.5 \%$ at 1 year, while repeat revascularization was $0.8 \%$ at day $0,2.0 \%$ at 30 days and $5.3 \%$ at 1 year. Acute stent thrombosis occurred in $0.3 \%$ at day 0 , in $0.8 \%$ at 30 days and in $1.4 \%$ at 1 year. Major bleeding occurred in $5.6 \%$ at day 0 , in $6.4 \%$ at 30 days and in $9.2 \%$ at 1 year. Patients who arrived $>3 \mathrm{~h}$ from onset of symptoms had a higher rate of $\mathrm{MI}$ at 1 year $(1.4 \% \mathrm{vs} .8 \%$ in $<3 \mathrm{~h}$; $\mathrm{P}$ $=0.008)$. Further, patients in whom a first balloon inflation occurred $>1 \mathrm{~h}$ after arrival in the catheterization laboratory had a higher rate of recurrent $\mathrm{MI}$ at day $0(0.6 \% \mathrm{vs} .0 \%$ in $<1 \mathrm{~h}$; $\mathrm{P}$ $=0.007)$, at 30 days $(0.8 \%$ vs. $0 \%$ in $<1 \mathrm{~h} ; \mathrm{P}=0.001)$ and at 1 year $(1.4 \%$ vs. $1.1 \%$ in $<1 \mathrm{~h} ; \mathrm{P}=0.012)$ (Table 2$)$.

\section{Time delays}

The overall delay

Median time from symptom onset to arrival at the hospital was $156 \mathrm{~min}$. Of the patients, $57.4 \%$ arrived within $3 \mathrm{~h}$ and $42.6 \%$ after $3 \mathrm{~h}$. Median time from hospital arrival to catheterization laboratory arrival was $20 \mathrm{~min}$. Of the patients, 59.4\% arrived within $30 \mathrm{~min}$ and $40.6 \%$ after $30 \mathrm{~min}$. Median time from hospital arrival to first balloon inflation (door-to-balloon time) was $69 \mathrm{~min} ; 63.3 \%$ of the patients were treated within $90 \mathrm{~min}$ and $36.7 \%$ after $90 \mathrm{~min}$. Finally, median time from catheterization laboratory arrival to first balloon inflation was $36 \mathrm{~min}$; $78.4 \%$ of the patients achieved within $60 \mathrm{~min}$ and $21.6 \%$ after 60 min (Figs. 1 and 2).

\section{Delays and patient characteristics}

Patients with history of a previous MI or PCI had a shorter time from symptoms onset to hospital arrival $(\mathrm{P}=0.004)$.

\section{Delays and time and day of presentation}

We further found that patients presenting at night time $(\mathrm{n}=$ 100) had slightly longer median door-to-balloon time (74 $\mathrm{min})$ than those arriving at office hours $(68 \mathrm{~min})$ at office hours, while the former group required more than $90 \mathrm{~min}$ in $42 \%$ of the patients, and in the latter only $33.9 \%$ had such a long door-to-balloon time $(\mathrm{P}=0.012)$. Furthermore, overall median door-to-balloon time was 89 min at weekends and public holidays $(\mathrm{n}=101)$, but 68 min during office hours. Again, door-to-balloon time was more than $90 \mathrm{~min}$ in $47.5 \%$ of patients presenting at such days, but only $31.7 \%$ of those arriving during office hours $(\mathrm{P}=0.023)$. Median time from hospital arrival to cathlab during night hours was $20 \mathrm{~min}$ and similar to office hours. During night hours, $39.8 \%$ of patients took more than $30 \mathrm{~min}$ versus $40.9 \%$ of those arriving during day hours $(\mathrm{P}=0.843)$. The median time at weekends and public holidays was 30 and 15 min during office hours with $48.6 \%$ of the patients arriving after $30 \mathrm{~min}$ at weekends and public holidays and $37.5 \%$ during office hours $(\mathrm{P}=0.034)$. Lastly as regards median time from cathlab arrival to first balloon inflation, this averaged 37 min during office hours, but $36 \mathrm{~min}$ at night time, and $35 \mathrm{~min}$ at weekends. Time from cathlab arrival to first balloon inflation of more than $1 \mathrm{~h} \mathrm{oc}-$ curred in $20.6 \%$ of patients arriving at weekends and in $22 \%$ in those presenting during office hours $(\mathrm{P}=0.782)$. The corresponding values for at night time and office hours were $22.9 \%$ and $20.9 \%$, respectively $(\mathrm{P}=0.685)$.

\section{Time delays in resuscitated patients}

A total of 23 resuscitated STEMI patients, of which 16 patients had received out-of-hospital resuscitation and seven patients with in-hospital resuscitation, had a median time from symptoms onset to hospital arrival of $188 \mathrm{~min}$ as compared to 155 min in non-resuscitated patients. Median door-to-balloon time was $93 \mathrm{~min}$, but $65 \mathrm{~min}$ in non-resuscitated patients. Median time from hospital arrival to first balloon inflation averaged 45 min, but only $15 \mathrm{~min}$ in non-resuscitated patients. Median time from cathlab arrival to first balloon inflation was $44 \mathrm{~min}$, but 

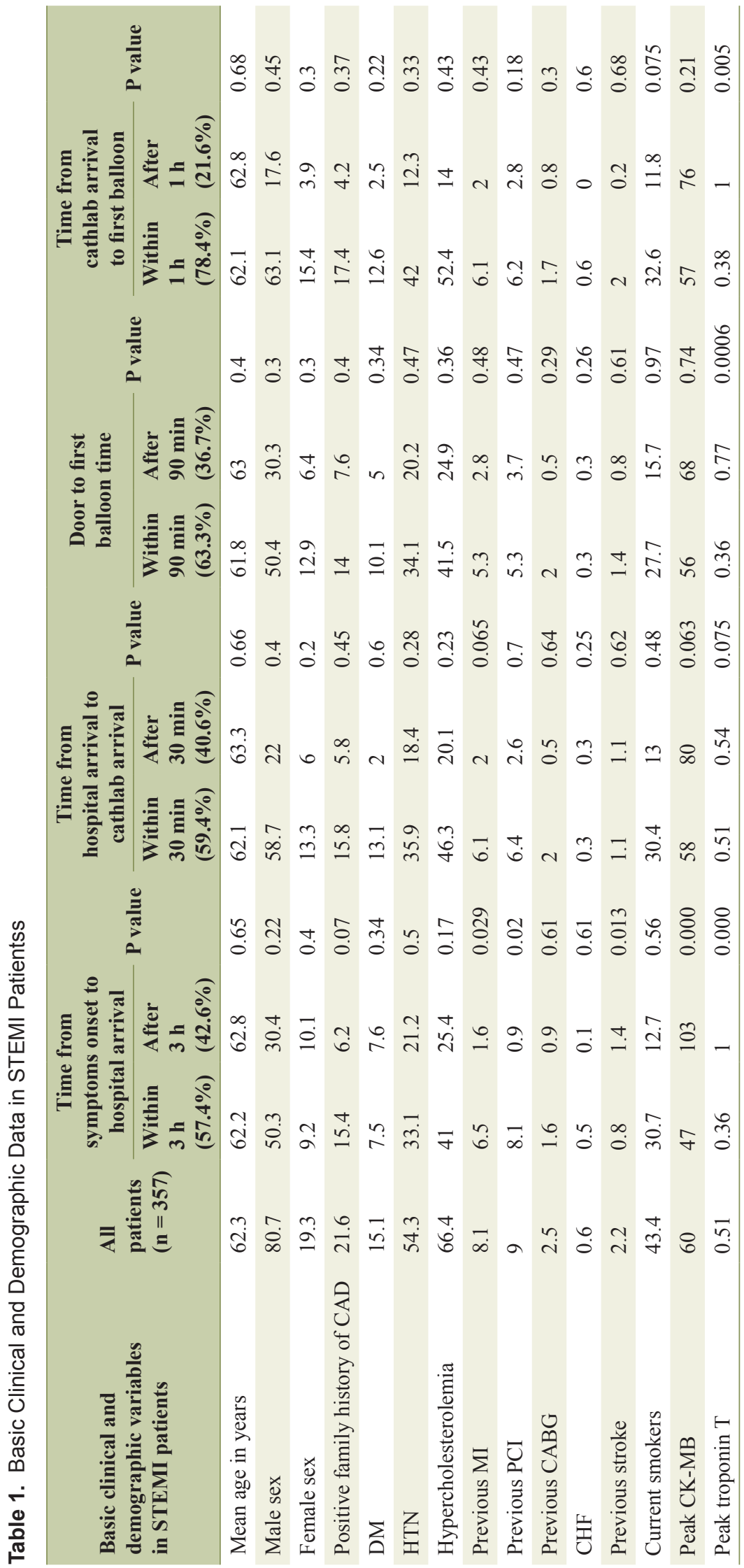


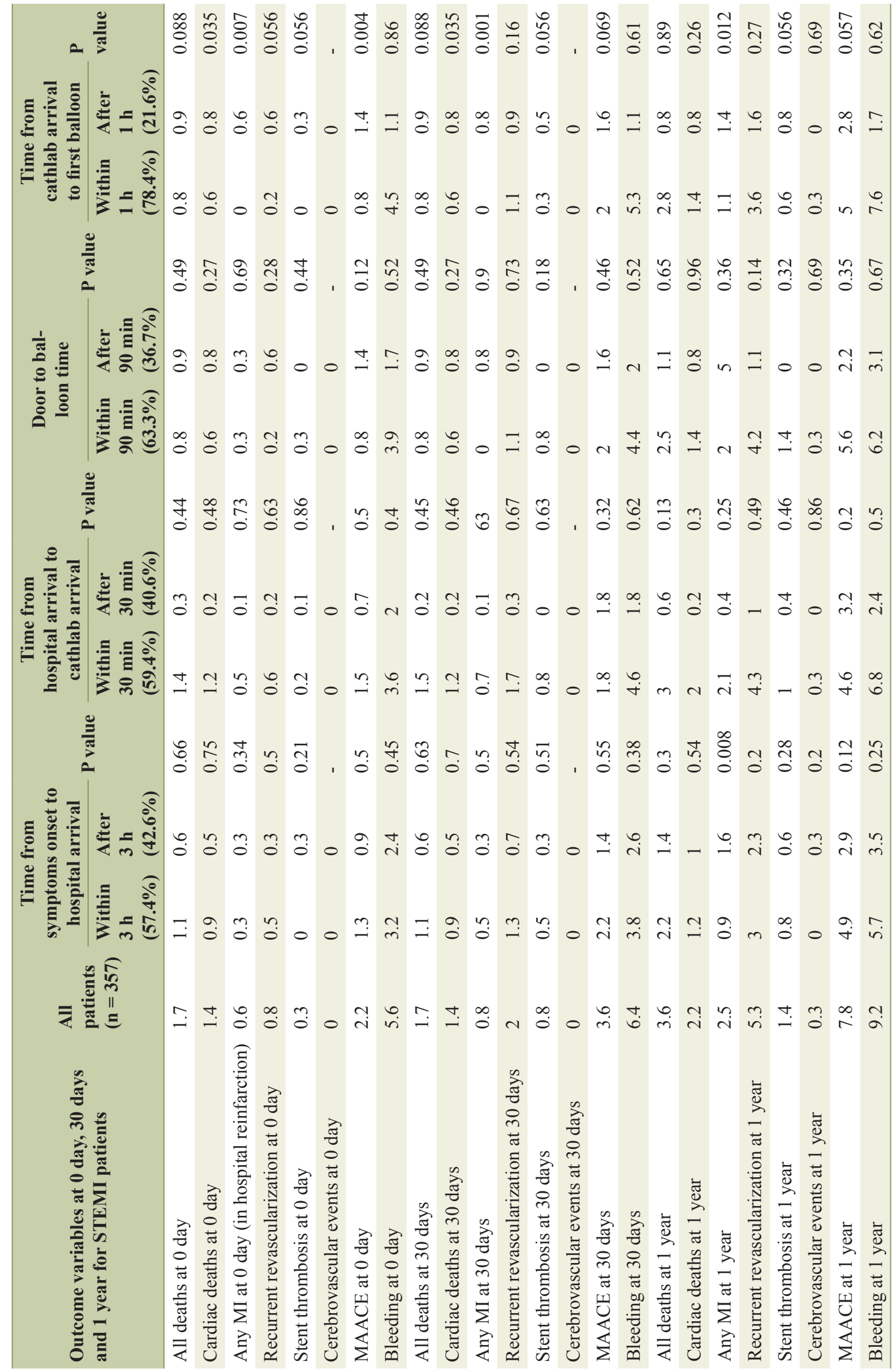




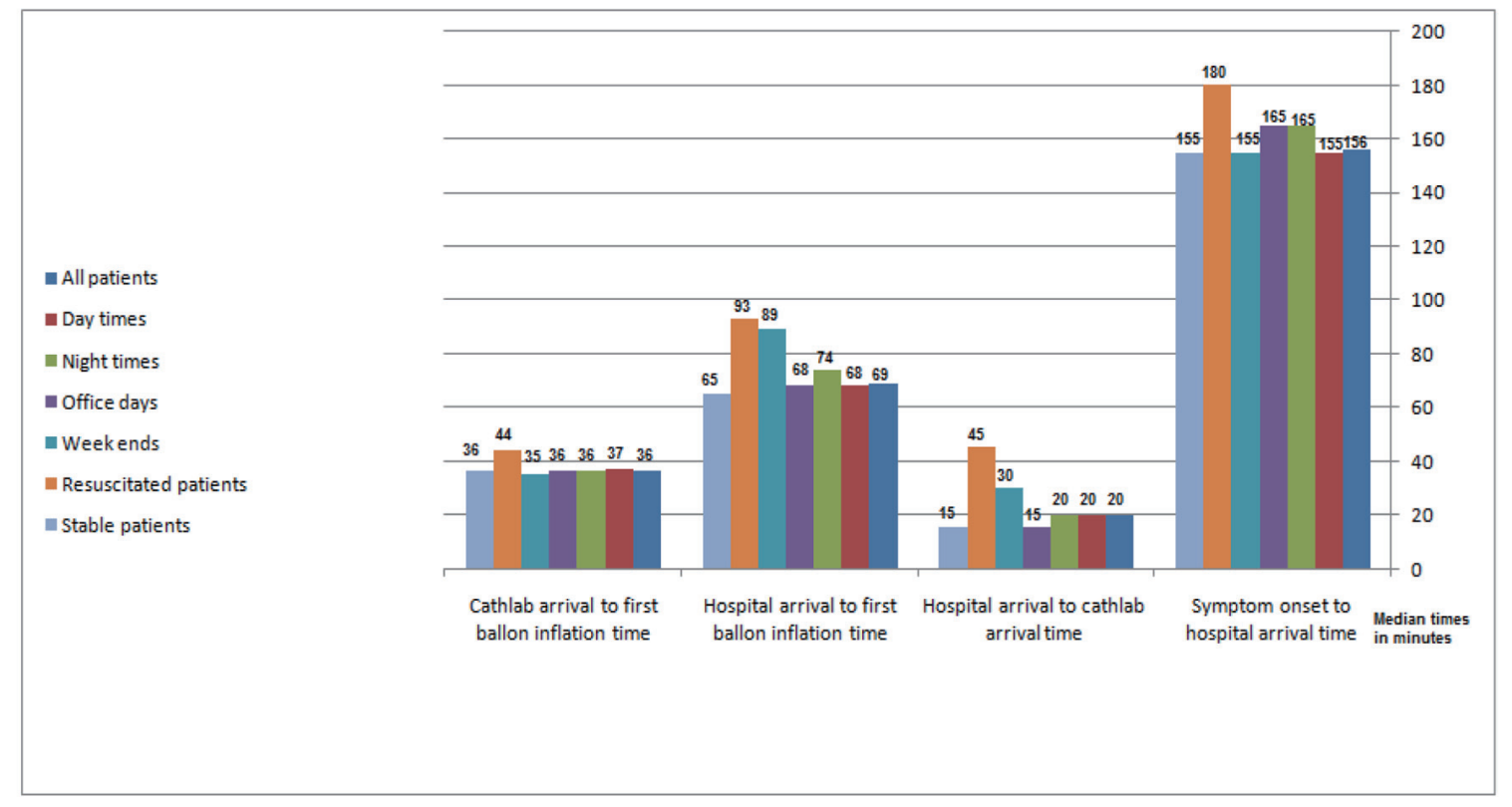

Figure 1. Mean time intervals in minutes to primary PCI in STEMI in different patient groups.

only $36 \mathrm{~min}$ in non-resuscitated patients.

\section{Time delays and infarct size}

Late arrivals from symptoms onset to hospital entry had significantly higher peak $\mathrm{CK}-\mathrm{MB}$ and higher high-sensitivity troponin $\mathrm{T}$ levels than early arrivals. Similarly, patients with prolonged time from hospital to arrival to the catheterization laboratory, longer door-to-balloon time or time from catheterization laboratory arrival to first balloon inflation had significantly higher levels of peak troponin $\mathrm{T}$ levels than early arrivals.

\section{Total ischemic time}

Median total ischemic time was longer for patients presenting

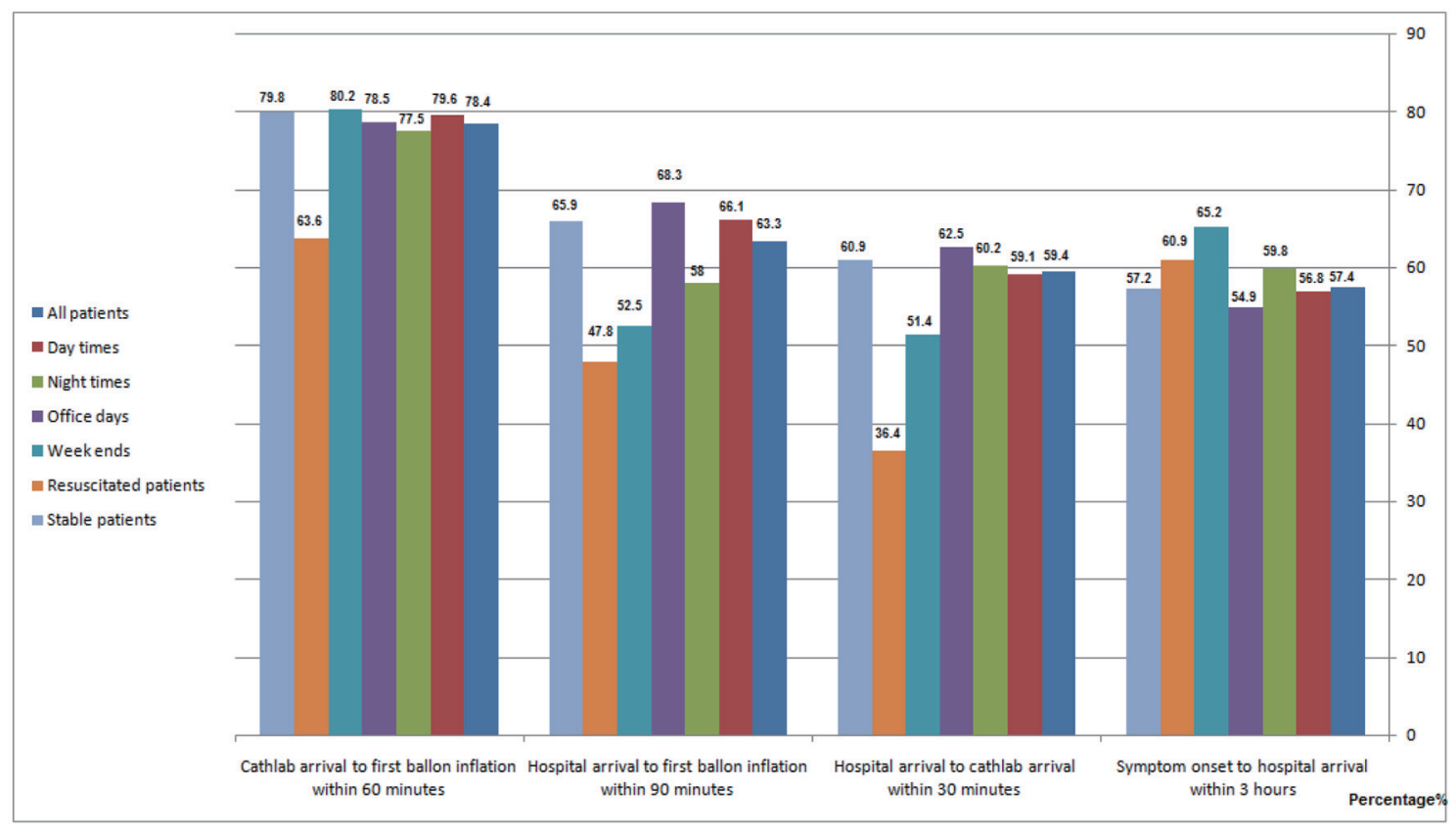

Figure 2. Percentage of patients managed earlier in relation to patients presentation. 
at weekends, at night hours and resuscitated patients, was 225 min for all patients, $223 \mathrm{~min}$ at day hours, $239 \mathrm{~min}$ at night hours, $244 \mathrm{~min}$ at weekends, $233 \mathrm{~min}$ at office days, $220 \mathrm{~min}$ in stable patients and $273 \mathrm{~min}$ in resuscitated patients.

\section{Discussion}

In current study, we found that STEMI patients who arrived > $3 \mathrm{~h}$ from onset of symptoms had a significantly higher percentage of MI at 1-year follow-up; furthermore, patients who had a delay of $>1 \mathrm{~h}$ from arrival at the catheterization laboratory to first balloon inflation had a higher rate of recurrent $\mathrm{MI}$ at day 0 , at 30 days and at 1 year as well as a higher rate of cardiac deaths at these time points. Time delays in STEMI patients included patient's delay along with delays in pre-hospital management, in-hospital transportation to the catheterization laboratory and within the catheterization laboratory until a first balloon inflation. STEMI patients presenting at weekends or public holidays and to a lesser extent those arriving at night time exhibited more time delays and longer total ischemic time than those presenting at daytime or office hours; this finding agrees with recently published Japanese study 2017 which documented off hours presentation as a cause of delay to primary PCI in multicenter registry [6]. Although overall the delays were only in a minority of patients longer than the time periods recommended in current guidelines, our findings nevertheless show that even in experienced tertiary centers current real world practice should be further improved, indeed patient delays might be shorter with a broader knowledge about the clinical presentation of infarction in the population as $85 \%$ of our patients experienced the first event upon presentation; however, most of them $(80 \%)$ had any or several cardiovascular risk factors, physicians managing such patients must therefore inform them better about how and when to react in case of acute chest pain and/or dyspnea in order to shorten symptom onset to arrival time. In-hospital delays do require organizational measures both in the emergency department, transport services as well as in the catheterization laboratory in order to further shorten door-to-balloon-time. Previous studies mostly focused on symptom-to-PCI delays for example data from two small German studies involving only 264 patients reported no reduction in infarct size with primary PCI with decreasing symptom-to-PCI duration [7]. However, half of the patients in those studies had been treated by thrombolytic therapy. In line with our findings, other studies have found reduction in mortality with decreasing symptom-to-PCI delays [8, 9]. However, other studies have shown limited or no effect on mortality with shorter symptom-to-PCI delays [10-12]. The first of these two studies [11] considered $2 \mathrm{~h}$ as ideal door-to-balloon time. In a second study [12], only percutaneous transluminal coronary angioplasty was performed and there were no differences in 1- or 6-month mortality by time to reperfusion (6-month mortality: $<2 \mathrm{~h}(5.5 \%), 2$ to $<4 \mathrm{~h}(4.6 \%), 4$ to $<6 \mathrm{~h}$ $(4.5 \%),>6 \mathrm{~h}(4.2 \%), \mathrm{P}=0.97)$. There were also no differences in other clinical outcomes by time to reperfusion, except that reinfarction and infarct artery reocclusion at 6 months were more frequent with later reperfusion. Doing PTCA only and only follow-up for short period (only 6 months) explain the different results compared to our study. Thus, previous studies using symptom-to-PCI as a primary measure of time to treatment have been inconsistent with each other both regarding infarct size and clinical outcomes [13-15]. Several other studies have focused mainly on door-to-balloon time and showed convincing data regarding improved clinical outcomes with decreasing door-to-balloon times $[11,12,16]$. However, doorto-balloon time only focuses on the final part of the health care chain leaving out critical care elements where improvements could be achieved by appropriate measures. Our findings thus reinforce the current European Society of Cardiology guidelines on STEMI that state that a delay of 60 min or less from first medical contact to PCI is desirable, and that a timing of 90 min should be considered the upper limit [1]. Finally, an important lesson of the current study is that we also need to work on in-hospital delays either from hospital arrival to the catheterization laboratory or within catheterization laboratory and to provide a clear definition for ideal catheterization laboratory arrival to first-balloon-inflation time that reflects time delays within catheterization laboratory and hospital arrival to cathlab arrival time that reflects time in hospital delays.

\section{Study limitations}

Our study demonstrates results from a single center prospective cohort with retrospective data analysis with a moderate number of patients which in turn could benefit from validation in a larger population as part of a prospective trial. One limitation in our study comes from using the 2007 definition of MI which could have led to over diagnosis of MI.

\section{Incremental value}

In spite of gradual improvement of time to primary PCI in the last few years, there remain some factors that lead to delays in door-to-balloon time even in tertiary centers with a large case load as the current department. Importantly, we show that delay is also related to the time and day of presentation, in particular at weekends and public holidays stressing the need for logistic improvements particularly during such time periods. Furthermore, to reduce symptom onset to arrival times, it appears important that public education programmes are implemented to further reduce patient delays, while organizational measures should be considered to shorten time delays within the hospital and the catheterization laboratory, especially at weekend and night time.

\section{Acknowledgments}

This study was supported by the Swiss National Research Foundation (Special Programme University Medicine "ACS and Inflammation" Nr. 33CM30-124112), as well as unrestricted grants by AstraZeneca, Zug, Switzerland, Eli Lilly, IN, USA, Merck Sharpe and Dome (MSD), Lucerne; Sanofi- 
Aventis, Vernier; St. Jude Medical, Zurich, all Switzerland, a fellowship grant by Medtronic, Tollachenaz, Switzerland, and the Foundation for Cardiovascular Research - Zurich Heart House, Zurich, Switzerland. The SPUM consortium also received assays from Roche Diagnostics; Rotkreuz, Switzerland, Mohammady Shahin, MD was supported by a grant of mission's sector-ministry of higher education in Egypt. The authors wish to thank Anika Adam for her excellent management of the study and Dimitrios Nikolaides and his nursing team for their help in obtaining the time data.

\section{Conflict of Interest}

RK received lecture fees from Eli Lilly, Servier and Bayer Healthcare. FM has received research grants to the institution from Amgen, AstraZeneca, Boston Scientific, Biotronik, Medtronic, MSD, Eli Lilly and St. Jude Medical including speaker or consultant fees. SW has received research grants to the institution from Abbott, AstraZeneca, Boston Scientific, Biosensors, Biotronik, Cordis, Eli Lilly, Medtronic and St. Jude Medical. PJ is an unpaid steering committee or statistical executive committee member of trials funded by Abbott Vascular, Biosensors, Medtronic and St. Jude Medical. TFL received research grants to the institution from AstraZeneca, Bayer Healthcare, Biosensors, Biotronik, Boston Scientific, Medtronic, MSD, Merck, Roche and Servier, including lecture fees. CMM received research grants to the institution from Eli Lilly, AstraZeneca, Roche and MSD including speaker or consultant fees. All other authors have no conflict of interest to declare.

\section{Abbreviations}

ACEI: angiotensin converting enzyme inhibitor; ACS: acute coronary syndrome; ARBB: angiotensin receptor blocker; LBBB: left bundle branch block; BB: beta blocker; CABG: coronary artery bypass graft; $\mathrm{CAD}$ : coronary artery disease; CCB: calcium channel blocker; ECG: electrocardiogram; ESC: European Society of Cardiology; GRACE: Global Registry of Acute Coronary Events; MACCE: major adverse cardiac and cerebrovascular events; MI: myocardial infarction; NSTEMI: non-ST-elevation myocardial infarction; PCI: percutaneous coronary intervention; STEMI: ST-segment elevation MI; UA: unstable angina

\section{References}

1. Task Force on the management of STseamiotESoC, Steg PG, James SK, Atar D, Badano LP, Blomstrom-Lundqvist $\mathrm{C}$, Borger MA, et al. ESC Guidelines for the management of acute myocardial infarction in patients presenting with ST-segment elevation. Eur Heart J. 2012;33(20):25692619.

2. Gershlick AH, Banning AP, Myat A, Verheugt FW, Gersh BJ. Reperfusion therapy for STEMI: is there still a role for thrombolysis in the era of primary percutaneous coronary intervention? Lancet. 2013;382(9892):624-632.

3. Thygesen K, Alpert JS, White HD, Joint ESCAAHAWHFTFftRoMI. Universal definition of myocardial infarction. J Am Coll Cardiol. 2007;50(22):2173-2195.

4. Miedema MD, Newell MC, Duval S, Garberich RF, Handran CB, Larson DM, Mulder S, et al. Causes of delay and associated mortality in patients transferred with ST-segment-elevation myocardial infarction. Circulation. 2011;124(15):1636-1644.

5. Herrin J, Miller LE, Turkmani DF, Nsa W, Drye EE, Bernheim SM, Ling SM, et al. National performance on door-in to door-out time among patients transferred for primary percutaneous coronary intervention. Arch Intern Med. 2011;171(21):1879-1886.

6. Ikemura N, Sawano M, Shiraishi Y, Ueda I, Miyata H, Numasawa Y, Noma S, et al. Barriers associated with door-to-balloon delay in contemporary Japanese practice. Circ J. 2017;81(6):815-822.

7. Schomig A, Ndrepepa G, Mehilli J, Schwaiger M, Schuhlen H, Nekolla S, Pache J, et al. Therapy-dependent influence of time-to-treatment interval on myocardial salvage in patients with acute myocardial infarction treated with coronary artery stenting or thrombolysis. Circulation. 2003;108(9):1084-1088.

8. De Luca G, Suryapranata H, Ottervanger JP, Antman EM. Time delay to treatment and mortality in primary angioplasty for acute myocardial infarction: every minute of delay counts. Circulation. 2004;109(10):1223-1225.

9. Cannon CP, Gibson CM, Lambrew CT, Shoultz DA, Levy D, French WJ, Gore JM, et al. Relationship of symptomonset-to-balloon time and door-to-balloon time with mortality in patients undergoing angioplasty for acute myocardial infarction. JAMA. 2000;283(22):2941-2947.

10. Brodie BR, Stone GW, Morice MC, Cox DA, Garcia E, Mattos LA, Boura J, et al. Importance of time to reperfusion on outcomes with primary coronary angioplasty for acute myocardial infarction (results from the Stent Primary Angioplasty in Myocardial Infarction Trial). Am J Cardiol. 2001;88(10):1085-1090.

11. Brodie BR, Grines CL, Stone GW. Effect of door-toballoon time on patient mortality. J Am Coll Cardiol. 2006;48(12):2600; author reply 2601.

12. Muller UM, Eitel I, Eckrich K, Erbs S, Linke A, Mobius-Winkler S, Mende $M$, et al. Impact of minimising door-to-balloon times in ST-elevation myocardial infarction to less than 30 min on outcome: an analysis over an 8 -year period in a tertiary care centre. Clin Res Cardiol. 2011;100(4):297-309.

13. Eitel I, Desch S, Fuernau G, Hildebrand L, Gutberlet M, Schuler G, Thiele H. Prognostic significance and determinants of myocardial salvage assessed by cardiovascular magnetic resonance in acute reperfused myocardial infarction. J Am Coll Cardiol. 2010;55(22):2470-2479.

14. Hahn JY, Song YB, Gwon HC, Choe YH, Kim JH, Sung J, Choi SH, et al. Relation of left ventricular infarct transmurality and infarct size after primary percutaneous coronary angioplasty to time from symptom onset to balloon inflation. Am J Cardiol. 2008;102(9):1163-1169. 
15. Brodie BR, Webb J, Cox DA, Qureshi M, Kalynych A, Turco M, Schultheiss HP, et al. Impact of time to treatment on myocardial reperfusion and infarct size with primary percutaneous coronary intervention for acute myocardial infarction (from the EMERALD Trial). Am J Cardiol. 2007;99(12):1680-1686.
16. Blankenship JC, Scott TD, Skelding KA, Haldis TA, Tompkins-Weber K, Sledgen MY, Donegan MA, et al. Door-to-balloon times under $90 \mathrm{~min}$ can be routinely achieved for patients transferred for ST-segment elevation myocardial infarction percutaneous coronary intervention in a rural setting. J Am Coll Cardiol. 2011;57(3):272-279. 